\title{
Problem identification using function, mechanism and attributes of product
}

\author{
Suriati Akmal ${ }^{\mathrm{a}, \mathrm{b}^{*}}$, Nordeana Hashima ${ }^{\mathrm{a}}$, Saifudin Hafiz Yahaya $^{\mathrm{a}}$, H. Sihombing ${ }^{\mathrm{c}}$ and Yuhazri \\ Yaakob $^{\text {d }}$
}

${ }^{a}$ Faculty of Manufacturing Engineering, Universiti Teknikal Malaysia Melaka, Hang Tuah Jaya, 76100 Durian Tunggal, Melaka, Malaysia

${ }^{b}$ Innovative Software System \& Services Research Group, Centre for Advanced Computing Technology, Universiti Teknikal Malaysia Melaka, Hang Tuah Jaya, 76100 Durian Tunggal, Melaka, Malaysia

${ }^{c}$ Faculty of Technology Management and Technopreneurship, Universiti Teknikal Malaysia Melaka, Jalan Hang Tuah, 75300, Melaka, Malaysia

${ }^{d}$ Faculty of Technology Engineering, Universiti Teknikal Malaysia Melaka, Hang Tuah Jaya, 76100, Durian Tunggal, Melaka, Malaysia CH R O N I C L E ABS T R A C T

Article history:
Received: April 24, 2018
Received in revised format: June
24,2018
Accepted: August 9, 2018
Available online:
August 10, 2018
Keywords:
Problem-solving
Function
Mechanism
Attributes
TRIZ

\begin{abstract}
One of the primary objectives in product development is to reach an appropriate design perspective. This paper proposes a methodology, which uses functions, mechanisms, and attributes of the product to solve a design problem. The proposed approach works as a supporting methodology to assist young researchers as well as design engineers and the implementation of the method is demonstrated using a real-world case study of home appliances. A survey is conducted to identify six home appliances that have the highest frequency of daily use and to determine the one, which creates troubles for its users. The results of this study can be further used in TRIZ to identify innovative solutions.
\end{abstract}

\section{Introduction}

Problem-solving is highlighted as an important soft skill for engineering undergraduate students in Malaysia. Most universities impart good practices and knowledge to ensure the graduates who will become novice engineers and/or young researchers meet their needs on the market. However, the problem-solving skills of novice engineers and young researchers are often doubted by companies and universities. The process of transforming the theory and practical knowledge into a creative and innovative engineering solution is the challenge faced by novice engineers and young researchers (Venugopal et al., 2012). One of the strategies to improve problem-solving skills and to create innovative solutions is TRIZ (Harlim $\&$ Belski, 2010). The method has been used by novice engineers, experienced engineers and researchers for various applications such as the automotive industry (Tiuc \& Draghici, 2016), home life industry (Chen, 2010), electrochemical industry (Vries et al., 2011), engineering product development (Münzberg

* Corresponding author. Tel.: +6062702681

E-mail address: suriatiakmal@utem.edu.my (S. Akmal)

(C) 2018 by the authors; licensee Growing Science, Canada doi: $10.5267 /$ j.msl.2018.8.004 
et al., 2016), industrial design (Yang et al., 2012), building industry (Renev \& Chechurin, 2016), and sustainable innovation industrial development (Anna \& Cascini, 2011). TRIZ provides a guideline to formulate the problem and create innovative and creative solutions. The worsening/improving parameters in the contradiction matrix are identified and used to determine new possible engineering solutions for a product (Melemez et al., 2013). However, this method requires technical knowledge and brainstorming sessions as TRIZ analysis works at a high level of abstraction and generalization (Kamarudin et al., 2016). Also, the abstraction and generalization guides the design process by providing the most appealing solution to the novice designers (Kamarudin et al., 2016). Moreover, it is claimed that TRIZ lacks formalization of concept and techniques which implies some difficulties to implement the method (Najari et al., 2016; Cavallucci et al., 2011; Salustri \& Parmar, 2004). Consequently, a novice and/or young engineer lacks the understanding in providing inventive solutions.

This paper provides a brief summary of the problem identification of products through functions, mechanisms, and attributes. The definition of mechanism and attributes is adopted from another study (Pahl \& Beitz, 2013). Mechanism is defined as a logical assembly of components, elements, or parts, and associated energy and information flow that enables a machine, process, or system to achieve its included results. Attribute can be defined as the characteristics of a raw material or finished good which makes it distinct from other products (Guarino, 1992). Another definition made by Martin (1998) of the attribute of a product includes price, size and colour. All these attributes affect the product's appeal or acceptance in the market.

\section{Related works}

\subsection{Function}

Function can be defined as an activity that is natural to or the purpose of a person or thing (Oxford Dictionary, 2018). In other words, function is a kind of action or activity suitable for a person, thing, or, institution whereas the purpose is the reason something is designed or exists. The problem of product looks into what the product will have to do (Salustri et al., 2004). By focusing on function, the designer assumes a state of mind that is more open to new, innovative, and creative ideas, and less likely to commit the design.

\subsection{Mechanism}

According to Pahl and Beitz (2013) mechanism can be defined as a logical assembly of components, elements, or parts, and associated energy and information flow that enables a machine, process, or system to achieve its included result. A mechanism is usually a piece of a larger process or mechanical system. In the context of engineering, the mechanism can be defined as a device that transforms input forces and movement into a desired set of output forces and movement (Uicker et al., 2003). A mechanism is a machine that is a combination of resistant bodies arranged so that by their means, the mechanical forces of nature can be compelled to do work accompanied by a certain determinate motion (Moon, 2007).

\subsection{Attribute}

There are two types of attributes in order to define and characterize a product, which are hard attributes and soft attributes (Driver \& Johnston, 2001). These two attributes are radically different in nature. Hard attributes are objective and measurable (Sade, 2014). It relates to the function and performance of a product such as strength, speed, weight, and price. For example, if a product is too heavy, a designer must reduce the materials or components by using lighter materials. On the other hand, a soft attribute is subjective, emotional and cannot be quantified or measured by objective means. In general, the soft attributes are represented in words such as attractive, young, sporty, pleasant and feminine. These types of attributes are complicated and much related to the human psychology and feel. 


\section{Methodology}

In this study, a survey and interview were used to identify the product that a customer uses the most daily activities. For this purpose, a preferable product range to consider in this preliminary study is home appliances. Questionnaires were distributed to housewives at a residential area in Ayer Keroh, Melaka. Most of the people in that residential area were government servants and private sector workers. Almost 15 home appliances were listed in the questionnaire and the respondents were needed to rank them according to the frequency of usage. Additionally, an interview was conducted to understand the problem that customers encountered in a product. Subsequently, a list of customer's requirements was developed. The selection of the interviewee was randomly conducted. The next step was problem evaluation using two elements to describe product characteristics which are function, mechanism, and attributes. The final step was to apply TRIZ to identify innovative solutions.

\section{Results and discussion}

\subsection{The Proposed Methodology}

In this preliminary survey, only 30 out of 100 respondents gave the feedback. Most of the respondents selected the oven as the home appliance that was mostly used in daily life for many purposes. This was followed by the toaster, hand mixer, hair dryer, blender, and dishwasher. The authors called them the six products (6Ps). In order to identify the product that has more problems than the others, the following steps were taken into consideration:

Step 1: Identify functions, mechanism, and attributes for all products.

The selected 6Ps were analysed based on function, mechanism, and attribute. Each of the function, mechanism, and attributes of 6Ps were based on the definition in the literature review as listed in Table 1.

\section{Table 1}

The Function, Mechanism, and Attributes of Products

\begin{tabular}{|c|c|c|c|c|c|}
\hline Id. No & Function & Id. No & Mechanisms & Id. No & Attributes \\
\hline 1 & heat & $\mathrm{A}$ & thermal & $\mathrm{a}$ & filament \\
\hline 2 & timer & B & mass transfer & b & coil \\
\hline 3 & motion & $\mathrm{C}$ & chemical & $\mathrm{c}$ & wire \\
\hline 4 & cooking & D & electric & d & electrode \\
\hline 5 & insulation & $\mathrm{E}$ & nuclear & e & solenoid \\
\hline 6 & detection & $\mathrm{F}$ & steam & f & bearing \\
\hline 7 & seal & G & fluid & g & pulley \\
\hline 8 & starter & $\mathrm{H}$ & cut & $\mathrm{h}$ & wheel \\
\hline 9 & safety protection & I & blend & $\mathrm{i}$ & blade \\
\hline 10 & mixing & $\mathrm{J}$ & sensor & $\mathrm{j}$ & knife \\
\hline \multirow[t]{16}{*}{11} & cleaning & K & rotation & $\mathrm{k}$ & gear \\
\hline & & $\mathrm{L}$ & pumping & 1 & controller \\
\hline & & M & digital & $\mathrm{m}$ & relay \\
\hline & & $\mathrm{N}$ & thermostat & $\mathrm{n}$ & Alarm clock \\
\hline & & $\mathrm{O}$ & thermal fuse & o & motor \\
\hline & & $\mathrm{P}$ & housing/cover & $\mathrm{p}$ & compression spring \\
\hline & & Q & visible light & $q$ & magnet \\
\hline & & $\mathrm{R}$ & lock & $\mathrm{r}$ & roller \\
\hline & & $\mathrm{S}$ & coolant & S & belt \\
\hline & & $\mathrm{T}$ & wind & $\mathrm{t}$ & fan \\
\hline & & $\mathrm{U}$ & hot air & $\mathrm{u}$ & insulator \\
\hline & & $\mathrm{V}$ & gas sensor & V & cable \\
\hline & & W & signal & W & plunger \\
\hline & & $\mathrm{X}$ & axle & & \\
\hline & & $\mathrm{Y}$ & switch & & \\
\hline & & Z & door gasket & & \\
\hline
\end{tabular}


Step 2: Name the functions, mechanism, and attributes for all products using an identification number.

Numbers and alphabets were used as an identification number (ID No.) for function, mechanism, and attributes as listed in Table 1. Each function is represented with a numerical identification number, for example, 1 represents heat. Similarly, the mechanisms and attributes were given an identification number and alphabets in capital letters and small letters.

Step 3: Identify the functions, mechanism, and attributes of each product.

All the relevant functions, mechanisms and attributes in each 6P were then listed. Table 2 shows the functions, mechanism, and attributes for each $6 \mathrm{P}$.

\section{Table 2}

List of All Function, Mechanism, and Attributes of each Products

\begin{tabular}{llll}
\hline Product & Function & Mechanism & Attribute \\
\hline Oven & $1,2,6,8,9$ & A,B,F,J,M,N,O,P,Q,R,W,X,Y,Z & a,b,c,l,n,o,q,t,u,v,w \\
Toaster & $1,2,6,8,9$ & A,B,J, N,O,P,Q,R,Y & a,b,c,l,n,p,u,o \\
Hand mixer & $2,3,8,9,10$ & H,K,P,Y,N,R,A & $\mathrm{c}, \mathrm{i}, \mathrm{k}, 1, \mathrm{l}, \mathrm{v}, \mathrm{w}, \mathrm{a}$ \\
Hair dryer & $1,2,3,6,8,9$ & $\mathrm{~A}, \mathrm{~B}, \mathrm{~J}, \mathrm{O}, \mathrm{P}, \mathrm{U}, \mathrm{Y}$ & $\mathrm{a}, \mathrm{b}, \mathrm{c}, 1, \mathrm{o}, \mathrm{t}, \mathrm{v}, \mathrm{w}$ \\
Blender & $2,3,8,9,10$ & $\mathrm{H}, \mathrm{I}, \mathrm{K}, \mathrm{P}, \mathrm{Y}$ & $\mathrm{c}, \mathrm{i}, \mathrm{l}, \mathrm{o}$ \\
Dish washer & $1,2,5,6,7,9,11$ & $\mathrm{~A}, \mathrm{~B}, \mathrm{G}, \mathrm{J}, \mathrm{M}, \mathrm{N}, \mathrm{O}, \mathrm{P}, \mathrm{R}, \mathrm{S}, \mathrm{W}, \mathrm{X}, \mathrm{Y}, \mathrm{L}, \mathrm{Z}$ & $\mathrm{a}, \mathrm{b}, \mathrm{c}, \mathrm{e}, \mathrm{l}, \mathrm{n}, \mathrm{u}, \mathrm{v}, \mathrm{o}$ \\
\hline
\end{tabular}

Step 4: Calculate the frequency of functions, mechanism, and attributes in each product.

Based on Table 2, each function, mechanism, and attribute for the 6Ps were calculated. For example, the function of heat with ID No. 1 is relevant in four products such as oven, toaster, hairdryer, and dishwasher. Thus, the frequency of heat is four and was recorded in the column of frequency in Table 3. This step is repeated for all functions, mechanisms, and attributes for all 6Ps.

Table 3

Rank of the Function, Mechanism, and attributes

\begin{tabular}{|c|c|c|c|c|c|c|c|c|c|c|c|}
\hline \multirow{2}{*}{$\begin{array}{c}\text { Id } \\
\text { No. }\end{array}$} & \multirow[t]{2}{*}{ Function } & \multirow[b]{2}{*}{ 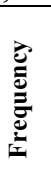 } & \multirow[b]{2}{*}{ 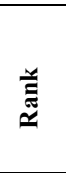 } & \multicolumn{3}{|c|}{ Mechanism } & \multicolumn{5}{|c|}{ Attribute } \\
\hline & & & & 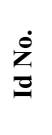 & & 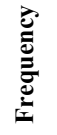 & 范 & $\underset{\text { ż }}{\stackrel{\dot{z}}{\Xi}}$ & & 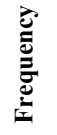 & 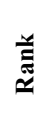 \\
\hline 1 & Heat & 4 & 3 & A & Thermal & 5 & 2 & $\mathrm{a}$ & Filament & 5 & 2 \\
\hline 2 & Timer & 6 & 1 & B & Mass transfer & 4 & 3 & $\mathrm{~b}$ & Coil & 4 & 3 \\
\hline 6 & Detection & 4 & 3 & $\mathrm{~J}$ & Sensor & 4 & 3 & $\mathrm{c}$ & Wire & 4 & 3 \\
\hline 8 & Starter & 5 & 2 & $\mathrm{~N}$ & Thermostat & 4 & 3 & 1 & Controller & 6 & 1 \\
\hline \multirow[t]{4}{*}{9} & safety protection & 6 & 1 & $\mathrm{O}$ & Thermal fuse & 4 & 3 & o & Motor & 6 & 1 \\
\hline & & & & $\mathrm{P}$ & Housing/cover & 6 & 1 & $\mathrm{v}$ & Cable & 4 & 3 \\
\hline & & & & $\mathrm{R}$ & Lock & 4 & 3 & & & & \\
\hline & & & & Y & Switch & 6 & 1 & & & & \\
\hline
\end{tabular}

Step 5: Rank the functions, mechanism, and attributes based on step 4.

In this step, the rank is equivalent to the frequency. Function (in case of function) that was found in more than three products was considered as the highest ranking. The rank was reported next to the column 
frequency in Table 3. For example, the timer and safety protection function represent the highest ranking in the 6Ps as they occur in all 6Ps.

Step 6: List the function, mechanism, and attributes that have a high ranking.

Based on Table 3, the function, mechanism, and attribute that have a ranking 1 and 2 were listed and considered as a relation. Subsequently, a relation between function, mechanism, and attribute can be created and in this study, the relation is combined randomly. Based on Table 3, the relation is shown in Table 4.

Table 4

Relation of Function, Mechanism, and Attributes

\begin{tabular}{cccc}
\hline Relation & Function & Mechanisms & Attributes \\
\hline $1(2, \mathrm{Y}, 1)$ & Timer & switch & Controller \\
$2(2, \mathrm{Y}, \mathrm{o})$ & Timer & switch & Motor \\
$3(9, \mathrm{P}, \mathrm{o})$ & safety protection & Housing/cover & Motor \\
$4(9, \mathrm{Y}, 1)$ & safety protection & switch & Controller \\
$5(8, \mathrm{Y}, 1)$ & Starter & switch & Controller \\
$6(8, \mathrm{Y}, \mathrm{o})$ & Starter & switch & Motor \\
\hline
\end{tabular}

\section{Step 7: Identify problem}

This step requires calculation of the summation of function, mechanism, and attributes for each product. In this step, only the highest-ranking functions, mechanisms, and attributes are considered (step 5). The overall total is the summation of total functions in 6Ps, a total mechanisms in 6Ps and total attributes in 6 Ps. The result of the overall total shows the product that always creates problems to the user. In this paper, the oven is considered as a home appliance that always creates problems to the user as shown in Table 5.

Table 5

Summation of Function, Mechanism, and Attributes

\begin{tabular}{llclclcc}
\hline \multicolumn{1}{c}{ Product } & Function & $\begin{array}{c}\text { Total } \\
\text { function }\end{array}$ & Mechanism & $\begin{array}{c}\text { Total } \\
\text { mechanism }\end{array}$ & Attribute & $\begin{array}{c}\text { Total } \\
\text { attributes }\end{array}$ & $\begin{array}{c}\text { Overall } \\
\text { Total }\end{array}$ \\
\hline Oven & $1,2,6,8,9$ & 5 & A,B,J,O,P,Y,N,R & 8 & a,b,c,l,o,v & 6 & 19 \\
Toaster & $1,2,6,8,9$ & 5 & A,B,J,O,P,Y,N,R & 8 & a,b,c,l & 4 & 17 \\
Hand mixer & $2,8,9$ & 3 & P,Y,N,R & 4 & c,l,o,v & 4 & 11 \\
Hair dryer & $1,2,6,8,9$ & 5 & A,B,J,O,P,Y & 6 & a,b,c,l,o,v & 6 & 17 \\
Blender & $2,8,9$ & 3 & P,Y & 2 & c,l,o & 3 & 8 \\
Dish washer & $1,2,6,9$ & 4 & A,B,J,O,P,Y,N,R & 8 & a,b,c,l,v & 5 & 17 \\
\hline
\end{tabular}

\subsection{The use of Proposed Methodology with TRIZ}

To further clarify the problem which occurs in the selected product, this step is required. Also, all functions, mechanisms, and attributes of the 6Ps are considered. If each 6P has the combination of all functions, mechanisms, and attributes, 1 will be written in the cell; otherwise, the number is 0 .

For example, the toaster in column relation 2 by referring to Table 5 has the function of the timer, 2, mechanism of the switch, Y, but no attributes of the motor, o. Thus, 0 was written in the cell that refers to the toaster. The purpose of this step is to identify the elements (function, mechanism, and attribute) that contradict each other using the TRIZ step. The step was repeated for all relations and the total of relations was determined and recorded as shown in Table 6. 
Table 6

Relationships between Function, Mechanism, and Attributes

\begin{tabular}{|c|c|c|c|c|c|c|c|c|c|c|}
\hline Relation & Function & Mechanism & Attribute & $\overbrace{0}^{0}$ & 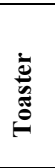 & 总 & 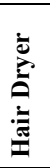 & 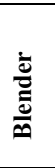 & 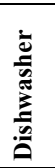 & है \\
\hline $1(2, Y, 1)$ & timer & Switch & controller & 1 & 1 & 1 & 1 & 1 & 1 & 6 \\
\hline $2(2, Y, o)$ & timer & Switch & motor & 1 & 0 & 1 & 1 & 1 & 1 & 5 \\
\hline $3(9, P, o)$ & safety protection & Housing / cover & motor & 1 & 0 & 1 & 1 & 1 & 1 & 5 \\
\hline $4(9, Y, 1)$ & safety protection & Switch & controller & 1 & 1 & 1 & 1 & 1 & 1 & 6 \\
\hline $5(8, Y, 1)$ & starter & Switch & controller & 1 & 1 & 1 & 1 & 1 & 1 & 6 \\
\hline $6(8, Y, o)$ & starter & Switch & motor & 1 & 0 & 1 & 1 & 1 & 1 & 5 \\
\hline
\end{tabular}

Below are procedures to follow in TRIZ which starts with the contradiction matrix:

Step 1: Define problem

Define the elements (function, mechanism, and attribute) of the design that is required to be improved.

Step 2: Analyse problem.

Analyse problem statement in 39 TRIZ parameters by recognizing the enhancing parameter and intensifying the parameter that may be happen.

Step 3: Select Parameters.

Select parameters of worsening and improving. Identify the solution guidelines as a way to help the researchers remove the problem. Once the parameter is unmistakably expressed, both the enhancing and intensifying parameter strife will be mapped to a $39 \times 39$ inconsistency grid and conceivable innovative standards will be proposed.

Step 4: Invention Principles.

Find invention principles that relate to the problem statement. Map these into the terms of the 39 parameters of the contradiction matrix to get pairs of improving-worsening features. The contradiction matrix then gives a few common solution principles. The recommended inventive principles are then received to propose solutions. There is a possibility that only a couple of principles could be utilized out of the most extreme four proposed principles from the contradiction matrix in light of the TRIZ expert's data and encounters. The designers are permitted to investigate the inventive principle of the 40 principles if none of the standards can possibly create a particular solution thought or idea.

Step 5: Solutions.

Develop and evaluate feasible solutions. Develop alternatives according to the corresponding invention principles and evaluate the feasibility.

Table 7 shows the analysis of TRIZ for an oven's problem. Based on this table, the principle of TRIZ was identified based on the contradiction between the worsening and improving of the parameter in which the parameter was selected based on the problem of the oven. After that, each principle for every problem of the oven was sorted to derive the best principle (green colour) to improve the product and achieve customer satisfaction. For example, for the overheating problem, we can conclude that the improving parameter is the quantity of substance or the matter (26), shape (12) and strength (14), while the worsening parameter is temperature (17) which does not improve the problem. After the contradiction analysis, the principles $3,17,39,22,14,19,32,30,10$ and 40 were the most popular for solving that class of problems. However, after the sorting process, the principles local quality (3), curvature (14), periodic action (19), and preliminary action (10) were the best principles to solve the problem and were best for a particular situation. 
Table 7

TRIZ Principles for Oven Product

\begin{tabular}{|c|c|c|c|c|c|c|c|}
\hline Problem & Improve & Worse & \multicolumn{5}{|c|}{40 Principle TRIZ (Based on Contradiction) } \\
\hline Overheat & $26,12,14$ & 17 & $3,17,39$ & $\begin{array}{l}22,14 \\
19,32\end{array}$ & $\begin{array}{l}30,10 \\
40\end{array}$ & & \\
\hline $\begin{array}{l}\text { Manual controller setting \& Controller- } \\
\text { not complete in cycle timer }\end{array}$ & $16,9,14$ & 37,25 & $\begin{array}{l}25,34,6 \\
35\end{array}$ & $\begin{array}{c}3,34,27 \\
18\end{array}$ & $\begin{array}{l}27,9,15 \\
40\end{array}$ & $\begin{array}{l}28,20 \\
10,16\end{array}$ & $\begin{array}{l}29,3,34, \\
10\end{array}$ \\
\hline $\begin{array}{l}\text { Temperature - no heat } \& \text { filament - no } \\
\text { heat }\end{array}$ & 16 & 25 & $\begin{array}{l}28,20 \\
10,16\end{array}$ & & & & \\
\hline Safety - no signal when broken & 27 & 24 & 10,28 & & & & \\
\hline $\begin{array}{l}\text { Controller - fan- heat not currently \& no } \\
\text { function }\end{array}$ & 17,21 & 13 & $1,35,32$ & $\begin{array}{l}35,32 \\
15,31\end{array}$ & & & \\
\hline $\begin{array}{l}\text { Timer - signal-thermostat light is not } \\
\text { coming }\end{array}$ & 21 & 37 & $\begin{array}{c}18,35 \\
16\end{array}$ & & & & \\
\hline Starter-stuck & 33 & 14 & $\begin{array}{l}32,40,3 \\
28\end{array}$ & & & & \\
\hline Motor - slow & 39,12 & $14,2,6$ & $\begin{array}{l}29,28 \\
10,18\end{array}$ & $\begin{array}{c}28,27 \\
15,3\end{array}$ & $\begin{array}{c}10,35 \\
17,7\end{array}$ & $\begin{array}{l}30,14 \\
10,40\end{array}$ & $\begin{array}{c}15,10 \\
26,3\end{array}$ \\
\hline Housing-not strength & 14,2 & 32 & $\begin{array}{l}11,3,10 \\
32\end{array}$ & $29,1,9$ & & & \\
\hline Switch - easy broken & 14 & 29,39 & 3,27 & $\begin{array}{r}29,35 \\
10,14\end{array}$ & & & \\
\hline
\end{tabular}

\section{Conclusion}

This paper has proposed a methodology that can be used by novice engineers and young researchers to identify a design problem. Prior to proposing a new design solution, it is a must for novice engineers and young researchers to have the capability to identify the problem. Based on the preliminary survey results, most of the respondents chose the oven, toaster, hand mixer, hair dryer, blender, and dishwasher as the home appliances used the most in daily life. The proposed methodology allows the novice engineer and young researcher to systematically evaluate problems for a product by decomposing it into functions, mechanisms, and attributes. As a result, the oven was determined as the product that creates the most problems to the user. Also, by identifying the functions, mechanisms, and attributes, the methodology facilitates users to identify parts that relate to functions, mechanisms, and attributes which are the cause of the problem for a product. Another advantage of the proposed methodology is that the results can be further used in TRIZ. This method is known as a decision-making tool in the design process that is capable of accelerating the search for inventive and innovative solutions for increasing customer satisfaction and improving product development. However, the abstraction in identifying the TRIZ parameters is time-consuming. The proposed methodology in this paper overcomes that limitation by identifying the functions, mechanisms, and attributes of each product. In this paper, the improving and worsening parameters of TRIZ for the oven were identified based on the higher relation of function, mechanism, and attributes. Later, the principles of TRIZ for the oven's problems were identified by the contradiction between improving and worsening parameters of TRIZ. The results show that it is possible to use the proposed methodology with other decision-making tools such as AHP and the Kano method.

\section{Acknowledgment}

All authors acknowledge the Faculty of Manufacturing Engineering and Innovative Software System \& Services Research Group, Universiti Teknikal Malaysia Melaka (UTeM) for research facilities and research collaboration.

\section{References}

Anna, W. D., \& Cascini, G. (2011). Supporting sustainable innovation through TRIZ system thinking. Procedia Engineering, 9, 145-156.

Cavallucci, D., Rousselot, F., \& Zanni, C. (2011). Using patents to populate an inventive design ontology. Procedia Engineering, 9, 52-62. 
Chen, H. (2010). Application of TRIZ and the Kano method to home life industry innovation. International Journal of Innovation and Learning, 7(1), 64-84.

Driver, C. and Johnston, R. (2001). Understanding service customers: the value of hard and soft attributes. Journal of Service Research, 4(2), 130-139.

Guarino, N. (1992). Concepts, attributes and arbitrary relations: some linguistic and ontological criteria for structuring knowledge bases. Data \& Knowledge Engineering, 8(3), 249-261.

Harlim, J., \& Belski, I. (2010). Young engineers and good problem solving: The impact of learning problem solving explicitly. In Proceedings of the 2010 AaeE Conference.

Kamarudin, K. M., Ridgway, K., \& Ismail, N. (2016). Abstraction and Generalization in Conceptual Design Process: Involving Safety Principles in TRIZ-SDA Environment. Procedia CIRP, 39(Dec 21), 16-21.

Martin, C. (1998). Relationship marketing: a high-involvement product attribute approach. Journal of Product \& Brand Management, 7(1), 6-26.

Melemez, K., Gironimo, G. D. I., Esposito, G., \& Lanzotti, A. (2013). Concept design in virtual reality of a forestry trailer using a QFD-TRIZ based approach. Turkish Journal of Agriculture and Forestry, 37, 789-801.

Moon, F. C. (2007). The Machines of Leonardo Da Vinci and Franz Reuleaux: kinematics of machines from the Renaissance to the 20th Century. Springer Science \& Business Media., 2.

Münzberg, C., Hammer, J., Brem, A., \& Lindemann, U. (2016). Crisis Situations in Engineering Product Development : A TRIZ based approach. Procedia CIRP, 39, 144-149.

Najari, A., Dubois, S., Barth, M., \& Sonntag, M. (2016). From Altshuller to Alexander: Towards a Bridge between Architects and Engineers. Procedia CIRP, 39, 119-124.

Oxford Dictionary. (2018). Definition of Function. Retrieved May 6, 2018, from https://en.oxforddictionaries.com/definition/function

Pahl, G., \& Beitz, W. (2013). Engineering design: a systematic approach. Springer Science \& Business Media.

Renev, I. A., \& Chechurin, L. S. (2016). Application of TRIZ in building industry : study of current situation. Procedia CIRP, 39, 209-215.

Sade, Y. (2014). The Two Different Types of Product's Attributes.

Salustri, F. A., \& Parmar, J. (2004). Product design schematics: structured diagramming for requirements engineering. In Product design schematics: structured diagramming for requirements engineering.

Tiuc, D., \& Draghici, G. (2016). TRIZ Model Used for Complaint Management in the Automotive Product Development Process. Procedia - Social and Behavioral Sciences, 221(13), 414-422.

Uicker, J.J., Pennock, G.R. and Shigley, J. . (2003). Theory of machines and mechanisms. In Oxford University Press, USA.

Venugopal, S., \& Davuluri, A. K. (2012). A Structured Framework for Training Technologists in Systematic Innovation. In IEEE International Conference on Teaching, Assessment, and Learning for Engineering (TALE) 2012.

Vries, R. W. De, Vaneker, T. H. J., \& Souchkov, V. (2011). Development of a framework for using TRIZ in a co-disciplinary design environment. Procedia Engineering, 9, 379-390. http://doi.org/10.1016/j.proeng.2011.03.127

Yang, C., Kao, C., \& Liu, T. (2012). An Innovative Product Design Approach Based on TRIZ' s Inventive Principles. International Journal of Systematic Innovation, 2(2), 1-8.

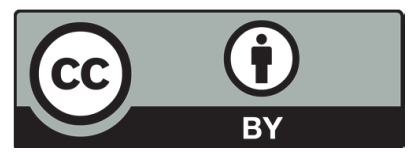

(C) 2018 by the authors; licensee Growing Science, Canada. This is an open access article distributed under the terms and conditions of the Creative Commons Attribution (CCBY) license (http://creativecommons.org/licenses/by/4.0/). 